\section{Using Equity Markets to Teach Long-Run Monetary Neutrality}

Stephen Miller

\section{Introduction}

Whenever I use the money market within a macroeconomic model, students frequently find it difficult to grasp the concept, because this money market differs from other real-world markets that students encounter and experience. In fact, the money market exists only as a fiction of economists' imagination. That is, no market exists explicitly to trade the medium of exchange, unit of account, and store of value.1 Rather, money facilitates exchange in every other non-barter market.

Monetary economists frequently invoke the classical dichotomy or monetary neutrality, whereby changes in the money supply exhibit nominal, but no real, effects. That is, changes in the money supply do not affect relative prices, but determine the level of prices. This dichotomy only emerges in the long run, according to conventional wisdom. Long-run monetary neutrality also implies that the money supply and the level of prices move proportionately. ${ }^{2}$ Short-run movements in the price level, however, do not typically move proportionately with the money supply, since money does not exhibit neutrality in the short run. Using equity markets to illustrate the concept of 'share-supply' neutrality in the short run provides students with some intuition as to why long-run monetary neutrality makes sense. Seeing monetary neutrality in action requires the use of the extreme situation of hyperinflation. ${ }^{3}$

This paper unfolds as follows. The next section discusses how the equity, or stock, markets operate and evaluates the responsiveness of price movements to changes in the supply of shares. The discussion illustrates that share prices adjust immediately to clear the market: that is, no distinction exists between the long- and short-run demands for and supplies of shares. A distinction does exist, however, between modelling the equity market in terms of 'flow' supply and demand curves versus 'stock' supply and demand curves. I then address the same issues in the money market with special attention to what the price of money means, something that did not arise in the equity-market discussion. Moreover, the presentation also must distinguish between the money market in macroeconomic models and common parlance in financial markets. Since a meaningful price of money comes only indirectly from other prices, that observation leads naturally to a distinction between long- and short-run demands for money.I then describe under what circumstances the equity market analogy conforms to actual events in the money market before finally concluding.

\section{The equity markets}

I begin by asking students if anyone owns shares (i.e., stock) of companies. Some students do. I ask them what their favourite is, and why. After some discussion, I pose a hypothetical question. I tell students that they each own 100 Intel Corporation shares, which currently trade at $\$ 50$ per share. ${ }^{4}$ Then, I tell them that tomorrow morning, they will hear on the news that overnight Intel implemented a two-for-one share split. We discuss what a two-for-one share split means. Finally, I ask what price they expect Intel shares to command when the market opens. Of course, they easily respond $\$ 25$, without giving it much thought.

Assuming that no student seems confused by the $\$ 25$ answer, I go on to ask someone to explain why he or she answered $\$ 25$. While I get lots of different responses, they generally fall in the category that 'nothing real changed'.5 That is, just because I now own 200 shares rather than 100 shares, this merely reflects a redefinition of the dollar value of each share. I should still own the same number of dollars even though the number of shares doubled. That is, the 'value' in dollars of my corporate ownership should remain unchanged. Given 100 shares at $\$ 50$, each student holds shares worth $\$ 5,000$. Then, the next morning, they still should still own Intel shares worth $\$ 5,000$. Thus, 200 shares implies a price of $\$ 25$ per share. No problem. The students pick this idea up with little difficulty.

Now, I tell the students that they just identified two points on their demand for Inte shares. That is, the company doubled the supply of shares overnight and the price per share fell by 50 per cent. The total dollar value of the outstanding shares did not change. What holds true for the individual demand curve also holds true for the aggregate demand curve for all Intel shareholders. I also suggest that I could consider numerous such share multiplications or contractions. But the general result does not change. For example, if Intel halves the supply of shares through a one-for-two reverse split, then the share price doubles. Such events illustrate 'share-supply neutrality'.6 
What does share-supply neutrality mean? The real yield on equity remains constant (neutral). Using the present value formula for a perpetuity, the real yield equals the net income stream per share (i.e. earnings per share) divided by the share price. Consequently, the real yield equals the net income stream divided by the share price times the number of shares. Thus, as the number of shares changes, say through a two-for-one share split, the price per share falls, halves for a two-for-one share split, keeping the real yield constant for a given net income stream (i.e. no change in fundamentals).

Next, I ask the students to consider the shape the demand curve traced out when I consider all possible supplies of Intel shares. This question proves more challenging for most undergraduates. But someone may volunteer that the demand curve would trace out a rectangular hyperbola relative to the price and quantity axes. Pushing the class further, I show the students that by dropping perpendiculars from any point of the hyperbolic demand curve to the price and quantity axes, I form a rectangle whose area measures the total dollar value of all shares. Since the dollar value of all shares does not change when I change the supply of the shares, each rectangle measures the same area (see Figure 1). Finally, I ask the students what this implies about the elasticity of a rectangular hyperbola demand curve. If I am lucky, someone will indicate unit elastic everywhere.

I emphasise that the discussion implicitly assumed that no changes occurred in the fundamentals of Intel's performance, no real change. If fundamentals improve, then the total dollar value of Intel shares should rise. In other words, if the net income stream rises, then the share price rises for a given supply of shares to keep the real

Figure 1: 'Stock' Demand for and 'Stock' Supply of Intel Shares

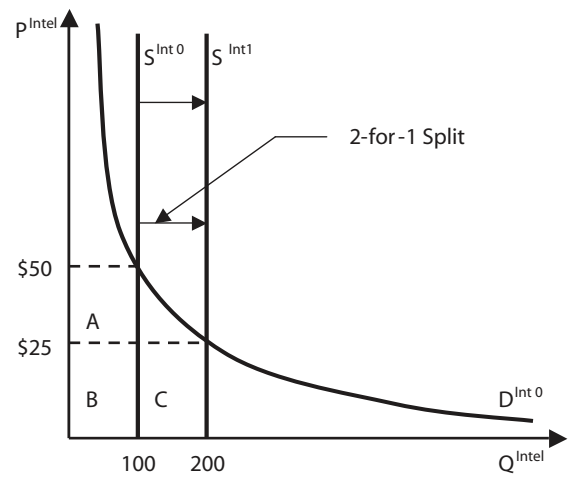

Note: $A+B=B+C=\$ 5,000$ yield constant. If the total supply of Intel shares does not change, then improved fundamentals should lead to a rightward shift of the hyperbolic demand curve, raising the price of every share.

Before leaving the equity market discussion, I typically make one final observation: even if fundamentals do not change, share ownership may transfer from one party to another on any given day. ${ }^{8}$ That is, each day a demand for and supply of exchanging share ownership exists. The demanders either do not currently own shares of the company that they want to own, or the demanders want to increase their existing holdings. Similarly, the suppliers either want to liquidate their holdings or lower the amount they currently hold. If the fundamentals do not change and if the quantity of shares supplied equals the quantity demanded, then this trading should occur at an unchanged price. ${ }^{9}$ Such daily trading rearranges the ownership structure of the total demand for the shares. In other words, price determination can occur in the 'flow' market for the existing supply of Intel shares or in the 'stock' market, where the demand for all shares meets the total supply of those shares. But these two markets must clear at the same price (see Figure 2). The 'stock' demand curve represents the demand to hold shares whereas the 'flow' demand represents the demand to acquire additional shares. The 'stock' supply curve represents the supply of shares, which instantaneously equals a fixed, unchanging amount. In other words, the 'stock' supply curve traces a vertical line and does not respond to changes in the price of Intel shares. The 'flow' supply curve represents the amount that current holders of the shares want to sell. This 'flow' supply curve implies that a higher price for Intel shares induces a larger quantity of shares offered for sale, a standard positively sloped supply curve.

Figure 2: 'Stock' and 'Flow' Demands for and Supplies of Intel Shares

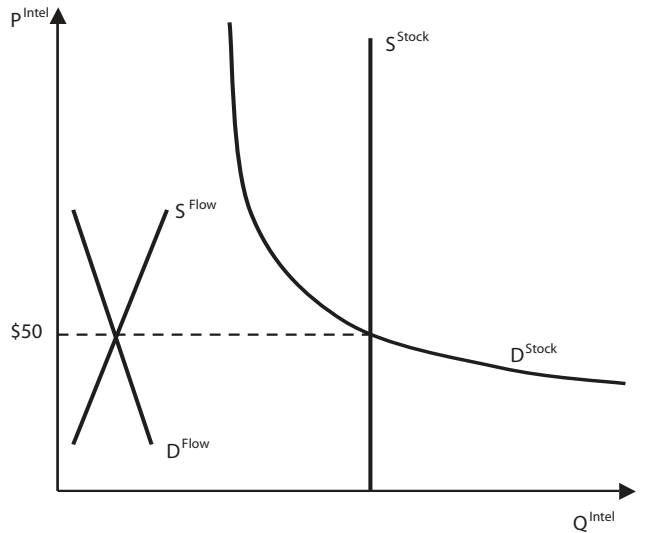




\section{The money market}

Before discussing the money market, I first must alert students to what economists mean by the money market and how it differs from common usage of that term in the financial markets. Most people think of the money market as a finance person does - that is, the markets for financial instruments with less than one-year to maturity. In macroeconomic models, however, the money market means the market for the medium of exchange, unit of account and store of value. Money facilitates the exchange of goods, services and financial instruments in every other non-barter market. But, no money market, itself, actually exists.

After differentiating between the money market and the market for short-term financial instruments, I next ask what the price of money is. Typically, students respond with the interest rate. At that point, I ask them how much they must pay to buy one dollar. A puzzled look usually comes over their faces, but usually at least one student will say one dollar. Since money incorporates the medium of exchange, unit of account and store of value functions, one dollar buys one dollar. Its price equals one. But that price conveys no information, since it is a tautology.

I tell the students that we need to determine the price of money indirectly, depending on what it purchases. Consider goods and services. For example, when Pizza Hut 'buys' money from customers, the price of money equals that fraction of a pizza given up for one dollar. For example, if pizzas currently sell at $\$ 10$ for a medium-sized pizza with all the works, then the price of one dollar equals onetenth of a pizza, or one divided by the price of pizzas. More generally, of course, the price of money equals one divided by some index of purchasing power, such as the consumer price index or the implicit price deflator for GDP.

Now, consider financial assets. When Barclays buys a one-year zero-coupon bond with face value of $£ 10,000$ from the UK Debt Management Office, they pay a price less than $£ 10,000$, since $£ 10,000$ tomorrow does not equal $£ 10,000$ today. The difference reflects the interest earned by Barclays from loaning their money for a year. ${ }^{10}$ In this sense, the interest rate does reflect a price of money (i.e. the price of money between today and some point in the future). Further, we can define this price more precisely, if the students know how to calculate a present value, especially for a perpetuity or consol. ${ }^{11}$ That is, the interest rate equals the coupon payment divided by the price of the perpetuity. Thus, the interest rate represents the number of perpetuities that the coupon payment buys. In that sense, the interest rate reflects the price of money in terms of how many bonds (assets) the interest earnings (coupon payment) can purchase. I stick with the standard convention, however, and define the price of money only in terms of the goods and services that money can buy. ${ }^{12}$
Now, after defining the price of money, I draw the analogy to the market for Intel shares. I ask the students what will happen to the prices of goods and services tomorrow morning if Ben Bernanke, Chairman of the Federal Reserve Board (Fed), announces on the late evening news that the Fed will engineer a two-for-one money split overnight.

Actual implementation of the two-for-one money split can generate some discussion about practical logistics. For example, the Fed, with the assistance of the commercial banks, can use electronic means to inflate all deposit accounts included in the 'official' definition of money by a factor of two. ${ }^{13}$ But, what about the currency and coin in circulation? Chairman Bernanke, and his elves, must act like Santa Claus and visit everyone, whether naughty or nice, and replace the currency and coin in their wallets and purses with double the amount.

Given a successful, albeit hypothetical, two-for-one money split, I moderate a discussion on what happens to spending decisions. That is, everyone now holds more money than they want to hold, assuming that they held the desired amount when they fell asleep last evening. I ask the students if Chairman Bernanke can force them to hold more money than they want to hold. No. If they hold too much money, it resembles the old children's game of 'hot potato'. Everyone tries to reduce his or her money holdings, passing the 'hot potato' as fast as possible, by buying goods, services or other assets. But try as they might, everyone collectively holds the extra money foisted on the economy by Chairman Bernanke. ${ }^{14}$

This exercise, among other things, illustrates the fallacy of composition. That is, what holds for the individual in the economy does not necessarily hold for the aggregate of all individuals. In this case, people must hold the existing supply of money. No dollars will get discarded, thrown away or destroyed. Dollars possess real value (i.e. purchasing power). Rather, the collective action of individuals in trying to reduce thei money holdings by purchasing assets, goods and services causes macroeconomic variables - the interest rate, real output and the price level - to adjust until everyone together, once again, willingly holds the existing supply of money.

Now, I return to the question of whether an overnight two-for-one money split will cause the price of money to halve tomorrow morning. The price of money equals the inverse of the price index of all goods and service in the markets. Thus, a halving of the price of money requires a doubling of prices of all goods and services. If true, then monetary neutrality emerges. That is, the increase in the money supply only affected nominal prices and produced no real effects (see Figure 3).

With the exception discussed in the next section, central banks do not operate in this fashion. Increases in the money supply occur because of either open market 
Figure 3: 'Long-Run 'Stock' Demand for and 'Stock' Supply of Money

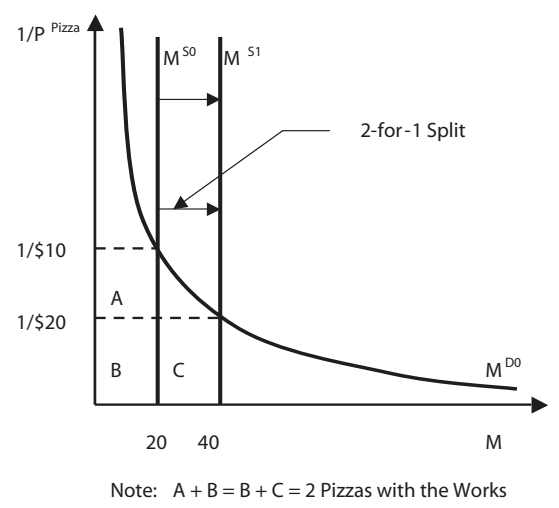

purchases or money financed government purchases. In either case, certain segments of the economy, government bond traders or government contractors (and employees), receive the additional money balances. The money injection does not get distributed in proportion to the initial holdings by economic agents (i.e. households, firms, and so on), as it must for a two-for-one money split. The injection of new money will affect spending decisions on goods, services and assets, as the excess money holdings get spent. Prices and production will increase and interest rates will fall. ${ }^{15}$ Thus, in the short run, increases (decreases) in the money supply exhibit real effects. Monetary neutrality does not characterise the short-run response to changes in the money supply. Now, something real does change in the short run. ${ }^{16}$

Over time, the holding of money will reallocate itself, coming closer and closer to the initial distribution of money holdings before the initial change in the money supply. The changes in the price level, production and the real interest rate pave the way toward a distribution of money holdings that agents willingly hold. In the long run, production and the real interest rate will return to where they started and only changes in the prices of goods and services will occur, producing monetary neutrality in the long run. In sum, the long-run money market exhibits monetary neutrality, but the short-run money market does not, since in the short run, prices adjust with a lag and monetary changes produce real effects. ${ }^{17}$

Two basic functions of money are the medium of exchange and store of value functions. The store of value function associates with the stock demand and stock supply curves that appear in textbooks. The medium of exchange function associates with the flow demand and flow supply of money that facilitates transactions. ${ }^{18}$ The flow supply of money comes from the demand for all other markets in the economy, whereas the flow demand for money come from the supply in all other markets, over a given time period. That is, when someone demands (supplies) a good or service, that person also supplies (demands) money in exchange, assuming money, not barter, exchange. In a long-run equilibrium situation, the flow demand and flow supply of money equate at the same price of money as the stock demand and stock supply of money equate. That proves analogous to the relationship between the flow demand and flow supply of equities and their corresponding stock demand and stock supply curves. That is, Figure 2 can also represent a relationship between the flow and stock demands and supplies of money.

When does the money market behave like the equity market?

I then ask students if they can think of a situation where the response of a two-forone money split mimics the response that occurs in the equity market to a similar share split. This question generally stumps the class, but occasionally I do find a student with the answer. In any event, I then relate the following fable.

\section{Fable of the irresponsible fiscal and monetary authorities 19}

I ask the students to imagine a country, the Land of Inflation, that recently experienced a long episode of hyperinflation. The central bank, the monetary authority, lost its credibility because it fuelled the hyperinflation by printing the money that the Ministry of Finance, the fiscal authority, needed to cover its burgeoning budget deficits. ${ }^{20}$

Under hyperinflation, even the lowest cost item eventually requires thousands or tens of thousands of currency units. The old government will probably get overthrown and replaced with a new one. This new government will appoint new governors of the central bank. The new government will demand that the new central bank administration address the inflation problem and break hyperinflation's back. The new head of the central bank will probably appear on national television and announce a currency reform. The central bank will issue a new currency unit worth, for example, 10,000 units of the old currency. In the interim, the old currency will still circulate until the central bank can replace it with the new currency. In effect, the action constitutes a 10,000-to-1 reverse money split. In addition, the central bank pledges to implement a responsible monetary policy and lower inflation to near zero.

I ask students what happens to prices the next morning. Answer: all prices reflect the new currency by dropping four zeros. For example, a price of 250,000 now 
equals 25 . So a currency reform mirrors a reverse share split. In that case, the demand for money equals a rectangular hyperbola and the short run merges with the long run, since prices adjust overnight.

Whether the central bank breaks the back of the hyperinflation depends on the credibility of the central bank's announcement. ${ }^{21}$ If the participants in the economy believe the announcement, then inflation can drop to near zero without substantia disruptions in economic activity. If the participants do not believe the announcement, then inflation will continue and substantial disruptions to economic activity will occur, as the central bank tries to delivers on its 'unbelievable' pledge.22

\section{Conclusion and application}

Understanding the money market in macroeconomic analysis proves challenging for the average student. Students typically learn from their own experience. Since an explicit money market does not actually exist, students find difficulty in seeing the intuition behind it. Rather, I use the equity market as an analogy to provide intuition about the money market. That analogy strictly holds only for a currency reform where one unit of a new currency replaces many units of the old currency. Along the way, I can take detours to cover important aspects of the money market. These detours offer students more intuition, which helps them better understand the role of the money market in the macroeconomic model.

The distinction between the long- and short-run demands for money does not generally appear in textbooks, however. ${ }^{23}$ Nonetheless, many textbooks still use the quantity theory of money, either to illustrate monetary neutrality or to derive the aggregate demand curve in the simplest way. The quantity theory of money provides the launching pad for jumping into the material covered in this paper.

\section{Notes}

In fact, currencies do trade for each other in international foreign exchange markets, where the price is the exchange rate. The money market in macroeconomic theory equates the demand for and supply of the medium of exchange, unit of account, and store of value. Confusion between the money market, as an economist defines it, and the foreign exchange market also exists in students' minds. But that lies outside the scope of the current discussion and constitutes an entirely separate paper.

2 The price level reflects an index of an economy's prices, such as the consumer price index or the implicit deflator for gross domestic product.

3 One referee notes:'Real-world inflationary processes are typically about aggregate supply and demand shocks - and the very tricky business of how interest-rate setting monetary policy tries to respond to those shocks. Students will gain no sense of this highly contingent process, from exercises such as this one.'I agree, but the current exercise provides the students with an intuitive feel for monetary neutrality, and not a careful analysis of short- and long-run monetary policy making.
4 I refrain from referring to Intel shares as stock, so as to not confuse shares with the 'stock' demand and supply curves. While easier to do in written form, lecturing probably results in the use of the words stock and shares interchangeably. It proves probably results in the use of the words stock and
helpful to mention the distinction to students.

5 Much research in the finance literature considers whether share splits signal changes in fundamental value. If the fundamental value does change and the share split signals new information, then something real changed and the opening price the next morning will differ from $\$ 25$. I ignore such complications.

6 A similar story applies to receiving shares through dividend distributions. For example, a 5 per cent share distribution will generate a 5 per cent fall in the share price, once again, assuming no change in fundamental value. New share issues, however, frequently occur because the firm intends to expand its operations and increase fundamental value. Then, something real does change. I ignore such activity.

7 Depending on the students in the class, I may not share this material in principles of macroeconomics. I do share it with students in higher-level classes. Most students intuitively accept the idea of share-supply neutrality. In principles of intuitively accept the idea of share-supply neutrality. In principles of
macroeconomics, many students may not know present value, especially the formula for a perpetuity.

8 Depending on the students in the class, I may not share the details of this material in principles of macroeconomics. I do share it with students in higher-level courses.

9 Of course, random noise in the market may cause short-run deviations from the market fundamental price. But, when that happens, the flow demand and supply equilibrium will shift to a higher (lower) price exactly in lock-step with the stock demand and supply equilibrium, where only the stock demand curve will shift.

10 A zero-coupon bond does not pay coupon interest. All interest comes from the difference between the price of the bond and its face value, if held to maturity. The implied interest rate equals the following: $\{(£ 10,000-P) / P\} \times 100$, where $P$ equals the price of the bond, and the price of the bond equals $\{£ 10,000 /(1+r)\}$, where $r$ equals the interest rate.

11 A government bond in Great Britain, originally issued in 1751, which pays perpetual interest and possesses no maturity date. Once again, depending on the students, I may not cover this material in principles of macroeconomics.

12 Some analysts argue that monetary policy with an inflation target proves misguided, if the price index only includes goods and services prices, and excludes asset prices. For example, The Economist argues that the monetary authorities should consider asset-price inflation (e.g. equity and real estate) when evaluating their monetary asset-price

13 Since economists still debate what items to include in the definition of money, the two-for-one money split proves much more complex than the two-for-one Intel share split.

14 As a side issue, note that disequilibrium in the money market always requires that market participants end up on the supply curve.

15 At this point, I generally discuss the timing of adjustments to an increase in the money supply - the real interest rate falls due to the liquidity effect followed by increases in production and then by increases in the price level. Moreover, as production and the price level rise, the real interest rate movement reverses itself and begins a return to its initial level, ignoring expected inflation. That is, short-run adjustment of the real interest rate precedes the intermediate adjustment of real output, which then precedes the long-run adjustment of the price level. 
16 Referring back to footnote 3 , this discussion takes the student into considering the real-world inflation process sparked by exogenous and policy shifts in aggregate demand and aggregate supply.

17 Mankiw (2004:461-464,351-357) discusses how the money market determines the interest rate in the short run as well as the price level and monetary neutrality in the long run, respectively.

18 I do not pursue this discussion in principles of macroeconomics. I may or may not delve into this area in higher-level courses.

19 To economists, this tells a 'Grimm Fairy Tale'.

20 If the monetary authority constitutes a division within the Ministry of Finance, then this response to the needs of the fiscal authority gets imposed within the bureaucracy.

21 Whether such announcements prove credible will also depend on whether a responsible fiscal policy gets implemented. The announcement may prove incredible even with a responsible fiscal policy, however. The private sector will doubt the credibility of the new government. The government first may need to prove itself.

22 Sargent (1986) provides extensive discussion of the ending of four hyperinflations.

23 Mankiw (2004) provides a notable exception. He first discusses the long-run demand for money in connection with the quantity theory of money and monetary neutrality. Later, he considers the short-run demand for money, which he uses to derive the aggregate demand curve.

\section{References}

Mankiw, N. G. (2004) Principles of Macroeconomics, 3rd edition, Thomson-South-Western Sargent, T.J. (1986) 'The Ends of Four Big Inflations.' In Rational Expectations and Inflation by T. J. Sargent, Chapter 3, Harper \& Row: New York, 40-109.

\section{Acknowledgement}

I gratefully acknowledge the comments and suggestions of W. McEachern, R. Cronovich and two anonymous referees.

\section{Contact details}

\section{Stephen M. Miller}

Professor and Chair of Economics

Department of Economics

University of Nevada

Las Vegas 4505 Maryland Parkway

Box 456005 Las Vegas

Nevada 89154-6005

Tel: $\quad$ (702) 895-3969

Email: stephen.miller@unlv.edu 